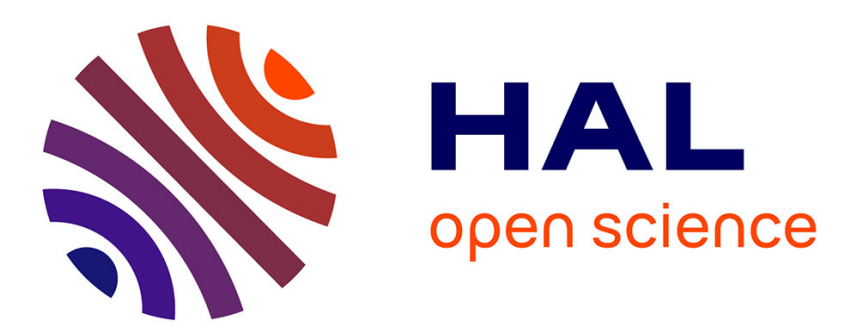

\title{
Holography and Holographic Interferometry with a near IR Sentitive photopolymer System
}

István Bányász, Daniel-Joseph Lougnot, Colette Turck

\section{To cite this version:}

István Bányász, Daniel-Joseph Lougnot, Colette Turck. Holography and Holographic Interferometry with a near IR Sentitive photopolymer System. Journal de Physique III, 1997, 7 (1), pp.211-222. 10.1051/jp3:1997120 . jpa-00249570

\section{HAL Id: jpa-00249570 https://hal.science/jpa-00249570}

Submitted on 1 Jan 1997

HAL is a multi-disciplinary open access archive for the deposit and dissemination of scientific research documents, whether they are published or not. The documents may come from teaching and research institutions in France or abroad, or from public or private research centers.
L'archive ouverte pluridisciplinaire HAL, est destinée au dépôt et à la diffusion de documents scientifiques de niveau recherche, publiés ou non, émanant des établissements d'enseignement et de recherche français ou étrangers, des laboratoires publics ou privés. 


\title{
Holography and Holographic Interferometry with a near IR Sensitive Photopolymer System
}

\author{
István Bányász $\left(^{*}\right)$, Daniel-Joseph Lougnot and Colette Turck \\ Laboratoire de Photochimie Générale (**), École Nationale Supérieure de Chimie de Mulhouse, \\ 3 rue Alfred Werner, 68093 Mulhouse Cedex, France
}

(Received 20 May 1996, accepted 9 October 1996)

PACS.42 40.Ht - Hologram recording and read-out methods

PACS.42 40.Kw - Holographic interferometry; other holographic techniques

PACS.82 35.+t - Polymer reactions and polymerization

\begin{abstract}
Holographic images of test targets were reconstructed from a new, self-processing photopolymer material. A laser diode operating at $780 \mathrm{~nm}$ was used in the experiments. Possible effects of the polarization of the construction beams on the reconstructed image were also studied. The applicability of this material to real tıme holographic interferometry was demonstrated.
\end{abstract}

\section{Introduction}

Although laser diodes emitting in the near-infrared range have long been manufactured, the lack of suitable recording materials considerably delayed their application in optical holography Silver halide materials have been used for the first holographic recordings in the near infrared [1]. Their sensitivity in the IR, however, is about six orders of magnitude lower than in the visible range.

Holography with photopolymer materials has first been reported in the late sixties [2,3]. The first experiments have been followed by vigorous research activities and the development of photopolymer materials became one of the most dynamically developing branches of holography $[4-8]$.

A range of photopolymer holographic recording materials has been developed in the "Laboratoire de Photochimie Générale", such as biphotonic systems $[9,10]$ and self-developing materials [11-13]. Green-sensitive systems have first been devised, and their usability in holographic interferometry [11] and holographic optical elements [14] has been demonstrated. New systems exhibiting a fairly high sensitivity at red laser lines e.g. at 633 and $647 \mathrm{~nm}$ have recently been reported [15].

The aim of the present work was to record holograms with a medium-power laser diode operating at $780 \mathrm{~nm}$. To achieve this purpose, a new formulation sensitized at this wavelength was devised in the laboratory. Evidence was provided that bright images of high spatial resolution can be reconstructed from holograms recorded in this material. Several series of

(*) Author for correspondence (e-mail banyasz@alpha0.ikı.kfki.hu).

Permanent address: Institute of Isotopes, Budapest, P.O.B 77, 1525, Hungary

$\left({ }^{* *}\right)$ U.R A. au CNRS 431

(C) Les Éditions de Physique 1997 


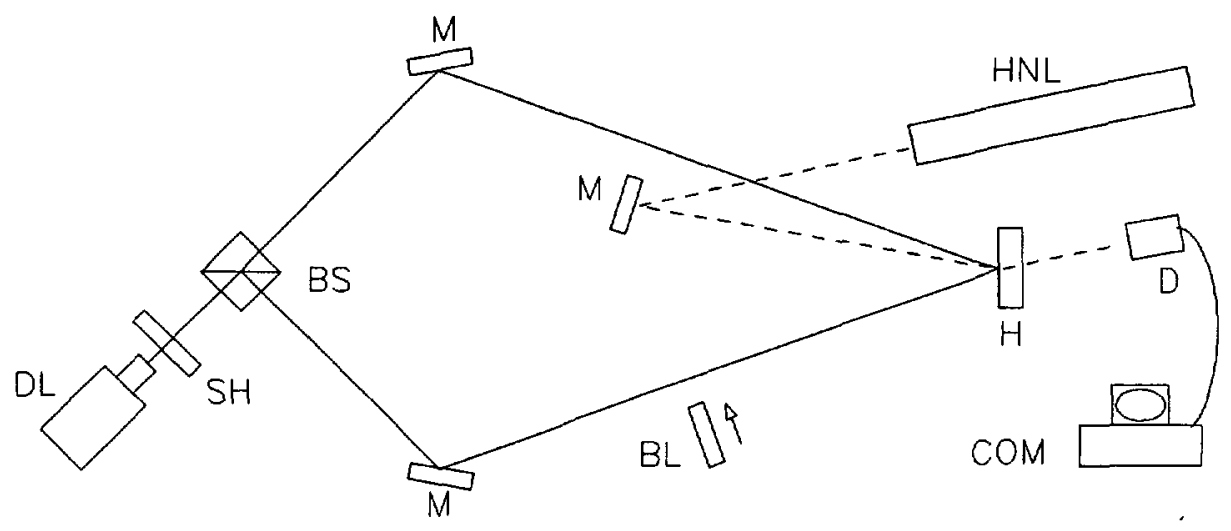

Fig 1 - Set-up for hologram recordıng. DL = diode laser $(\lambda=780 \mathrm{~nm}), \mathrm{HNL}=\mathrm{He}-\mathrm{Ne}$ laser $(\lambda=543 \mathrm{~nm}), \mathrm{M}=$ mirrors, $\mathrm{BS}=$ beam-splitting cube, $\mathrm{H}=$ hologram, $\mathrm{D}=$ detector, $\mathrm{COM}=$ computer, $\mathrm{SH}=$ shutter, $\mathrm{BL}=$ beamstop.

holograms of a resolution test target have been recorded in order to find optimum recording parameters. The usability of this material in real-time holographic interferometry was also demonstrated. It is hoped that these experiments will ultimately lead to the construction of compact holographic interferometers based on low-cost, maintenance-free laser diodes and this new photopolymer recording material.

\section{Experimental}

2.1. Determination of Holographic Characteristics of the Material. - The photopolymerizable material, consisting of a mixture of acrylate multifunctional monomers and oligomers with an initiating system working through a photoredox process, exhibited a fairly high sensitivity [16]. The absorption peak of this material was at $780 \mathrm{~nm}$, and, depending on the concentration of the sensitizer, a peak optical density of 2.7 with a halfwidth of $55 \mathrm{~nm}$ could be attained. In addition, this material that contained crosslinkable monomers and converted to a tridimensional network upon irradiation, showed a self-processing character allowing storage of optical information in situ. The mechanism of hologram formation in the near infrared sensitive material was similar to that in the green and red sensitive photopolymers $[10,11]$. The sample consisted of a thin layer of liquid polymer between two glass sheets. The thickness of the sample was fixed at $35 \mu \mathrm{m}$ by a spacer.

In a first stage plane wave holograms were recorded and reconstructed in the samples according to Figure 1. An SDL $5412 \mathrm{H} 1$ laser diode (DL) (manufactured by Spectra Diode Labs, Inc) was used. The temperature-stabilized laser operated in single longitudinal and TEM transversal mode at $\lambda=780 \mathrm{~nm}$ Its output was further shaped by an anamorphic beam expander. The reference and object beams impinged symmetrically on the hologram, making an interbeam angle of $40^{\circ}$. In the first series of experiments both the reference and the object beams were polarized perpendicularly to the plane of incidence. In a second one, the polarization of the reference and the object beams was changed to parallel to the plane of incidence. 


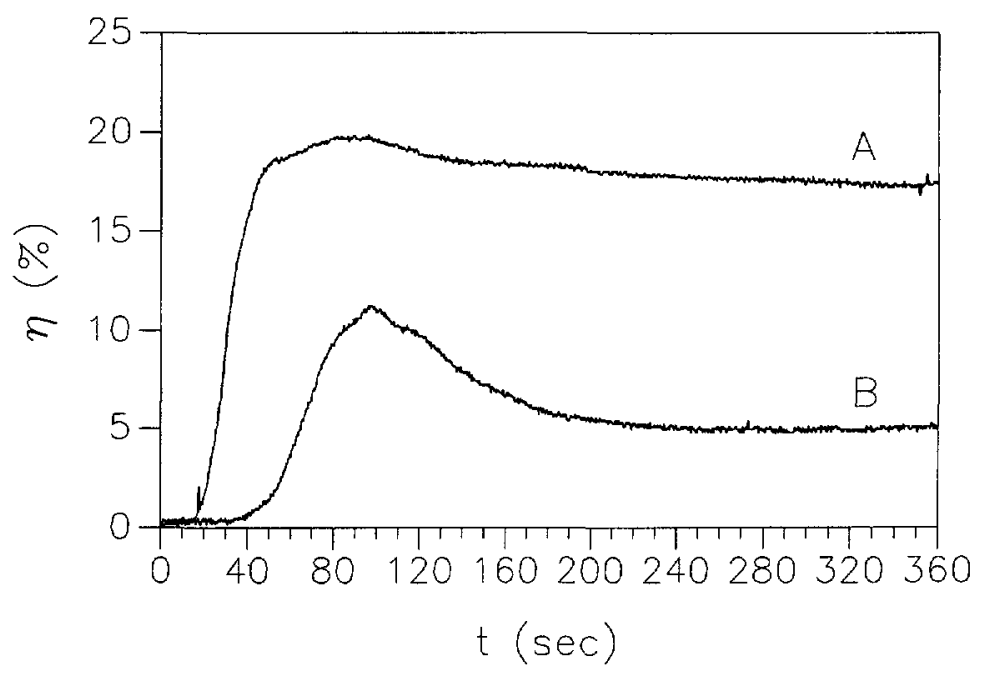

Fig 2 - Time-dependence of the diffraction efficiency of a holographic gratıng during recording. Curve A: perpendicular polarization. Curve B: parallel polarization.

The diffraction efficiency of the grating was monitored during its buld-up by a beam emerging from a He-Ne laser operating at $\lambda=543 \mathrm{~nm}$ and impinging at Bragg angle. This could be accomplished without destroying or perturbing the grating due to the fact that the extinction coefficient of the sample at $543 \mathrm{~nm}$ was three orders of magnitude lower than that at $780 \mathrm{~nm}$, so that the light of the monitor laser could be considered as inactinic. Several series of holograms were recorded under both parallel and perpendicular polarizations, with different total powers of illumination, beam ratios and sensitizer concentrations. By way of example. Figure 2 shows the buld-up of two holographic gratings recorded under different polarizations. Samples of the same batch (sensitizer concentration of $1.13 \mathrm{mg} \mathrm{g}^{-1}$ ) were used. Curve A refers to a hologram recorded by beams polarized perpendicularly to the plane of incidence, and curve $B$ refers to a hologram constructed by beams polarized parallel to the plane of incidence. The driving current of the laser diode was $100 \mathrm{~mA}$ in both cases. The exposure rate or total bias intensity of $50 \mathrm{~mW} \mathrm{~cm} \mathrm{~cm}^{-2}$ was also the same in both experiments. The reference wave was used to prepolymerize the samples. A uniform pre-exposure of $480 \mathrm{~mJ} \mathrm{~cm}{ }^{-2}$ was applied to sample A and $500 \mathrm{~mJ} \mathrm{~cm}^{-2}$ to sample $B$ to prepolymerize the material. The visibility of the interference pattern can be calculated by the following formula:

$$
V=\frac{2 \sqrt{R}}{R+1} \cos \Omega
$$

where $R$ is the ratio of the intensities of the reference and object beam and $\Omega$ the angle made by their directions of polarization. The visibility in the case of perpendicular polarization was 0.96 (due to a beam ratio of 1.78) and in the case of parallel polarization 0.77 (due to a beam ratio of 1.02 and an angle of $40^{\circ}$ subtended by the $\mathbf{E}$-vectors of the beams). The total duration of the holographic exposure was $420 \mathrm{~s}$ (A) and $360 \mathrm{~s}$ (B). Grating A began to build up after an inhibition period of $15 \mathrm{~s}$. A maximum diffraction efficiency of $20 \%$ was reached at $t=90 \mathrm{~s}$. As for grating $\mathrm{B}$, the inhibition period was $30 \mathrm{~s}$, and a maximum diffraction efficiency of $12 \%$ was reached at $t=95 \mathrm{~s}$. Note the pronounced drop in efficiency after the maximum in the case of parallel polarization. It must be added that the diffraction efficiencies measured by 
Table I. - Parameters of the first part of recordings. $R_{0}$ is the object-to-hologram distance, $I_{\mathrm{L}}$ the driving current of the laser diode, $I_{\mathrm{T}}$ the average total intensity of the holographic illumination, $I_{\mathrm{r}} / I_{0}$ the ratio of the intensity of the reference wave to the average intensity of the object beam, $t_{\mathrm{pp}}$ the time of prepolymerzzation and $t_{\exp }$ the range of exposure times.

\begin{tabular}{|c|c|c|c|c|c|c|}
\hline $\begin{array}{c}\mathrm{N}^{\circ} \text { of } \\
\text { series }\end{array}$ & $\begin{array}{c}R_{0} \\
(\mathrm{~mm})\end{array}$ & $\begin{array}{c}I_{\mathrm{L}} \\
(\mathrm{mA})\end{array}$ & $\begin{array}{c}I_{\mathrm{T}} \\
\left(\mathrm{mW} \mathrm{cm}^{-2}\right)\end{array}$ & $I_{\mathrm{r}} / I_{0}$ & $\begin{array}{c}t_{\mathrm{pp}} \\
(\mathrm{s})\end{array}$ & $t_{\exp }(\mathrm{s})$ \\
\hline I. & 90 & 100 & 32.1 & 35 & 60 & $86-344$ \\
II. & 90 & 100 & 25.6 & 34.6 & 60 & $106-590$ \\
III. & 90 & 100 & 25.3 & 389 & 60 & $106-590$ \\
IV. & 90 & 75 & 24.1 & 3.0 & 60 & $148-590$ \\
V. & 90 & 75 & 18.6 & 29.8 & 60 & $148-590$ \\
VI. & 45 & 130 & 35.6 & 33.3 & 60 & 100,140 \\
VII & 45 & 130 & 35.6 & 33.4 & 60 & 200 \\
\hline
\end{tabular}

the attenuated IR reference beam after the exposure were $25 \%$ for hologram $\mathrm{A}$ and $19 \%$ for hologram B. It is not certain that the differences in curves $A$ and $B$ are due to the different polarizations of the recording beams, since they may be attributed to the reduced visibility of the interference fringes at parallel polarization and the nonlinearity of the material, too. The dynamics of hologram build-up in this material will be discussed in detail in a later paper.

2.2. Quality of The Holographic Image. - To assess the capabilities of the recording material, several series of holograms of a negative USAF 1951 resolution test chart and of a special test object consisting of a three-element Ronchi grating with a grating constant of $16 \mu \mathrm{m}$ were recorded by using the set-up shown in Figure 1.

In the first part of the measurements, the reconstructed virtual images were observed by a CCD camera. To minimize exposure time, the laser beam emerging from the anamorphic telescope was not further expanded so that only the central part of the test chart was transilluminated. In part of the experiments, the distance between the test chart and the hologram was $90 \mathrm{~mm}$, while holograms with a separation of $45 \mathrm{~mm}$ were also recorded. The diameter of the laser beam was $10 \mathrm{~mm}$ and, therefore, the numeric aperture of the of the holograms was 0.055 in the first series and 0.11 for the second one. Holograms were recorded for different values of the driving current of the laser diode: 75,100 and $130 \mathrm{~mA}$. The beam ratio was changed by inserting appropriate filters in the object beam. The recording conditions are summarized in Table I. In all of these seven series, the polarization of the constructing beams was perpendicular to the plane of incidence, and samples with the same dye concentration $\left(0.93 \mathrm{mg} \mathrm{g}^{-1}\right)$ were used.

Five holograms obtained with different exposure times were recorded in each series. Virtual holographic images of the test object were reconstructed, and observed by a CCD camera. It was found that careful selection of the recording conditions made it possible to obtain holographic images with good resolution and brightness. Inspection of the image of the test object (Fig. 3a) and the best reconstructed holographic images (Figs. 3b and 3c) showed that in these experiments it was the objective of the CCD camera that limited the spatial resolution. The reconstructed images were of acceptable quality in spite of the coherent noise produced by spurious reflections from various surfaces in the optical set-up both at recording and reconstruction. 


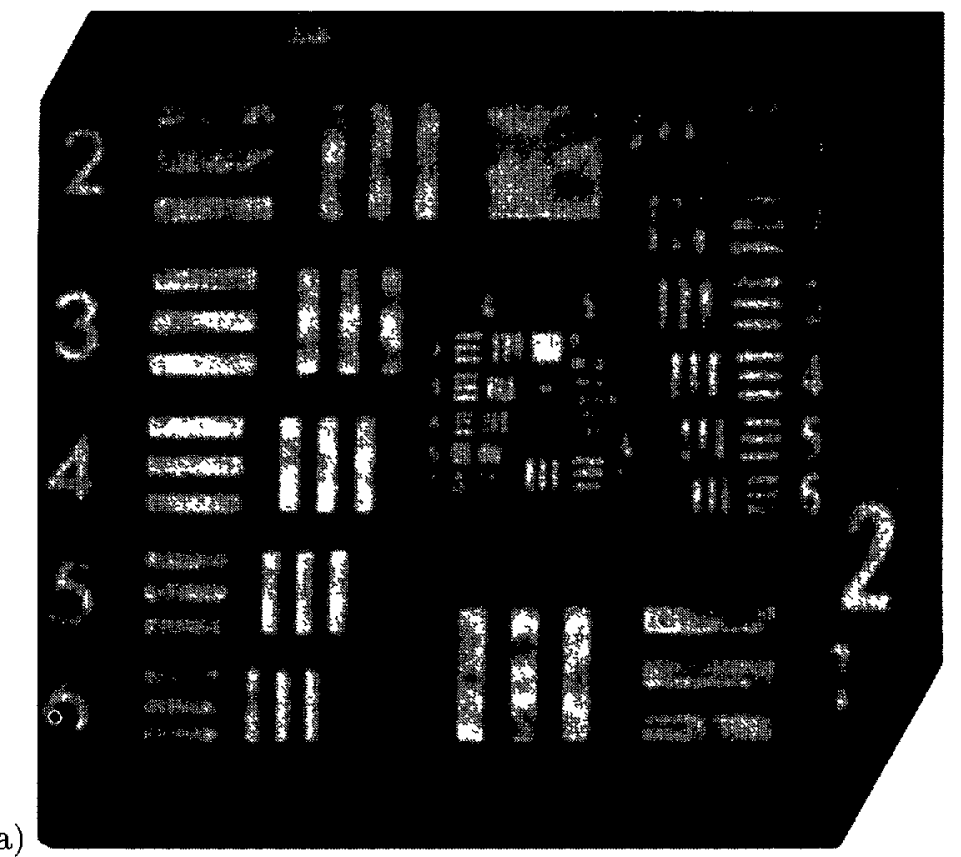

a)

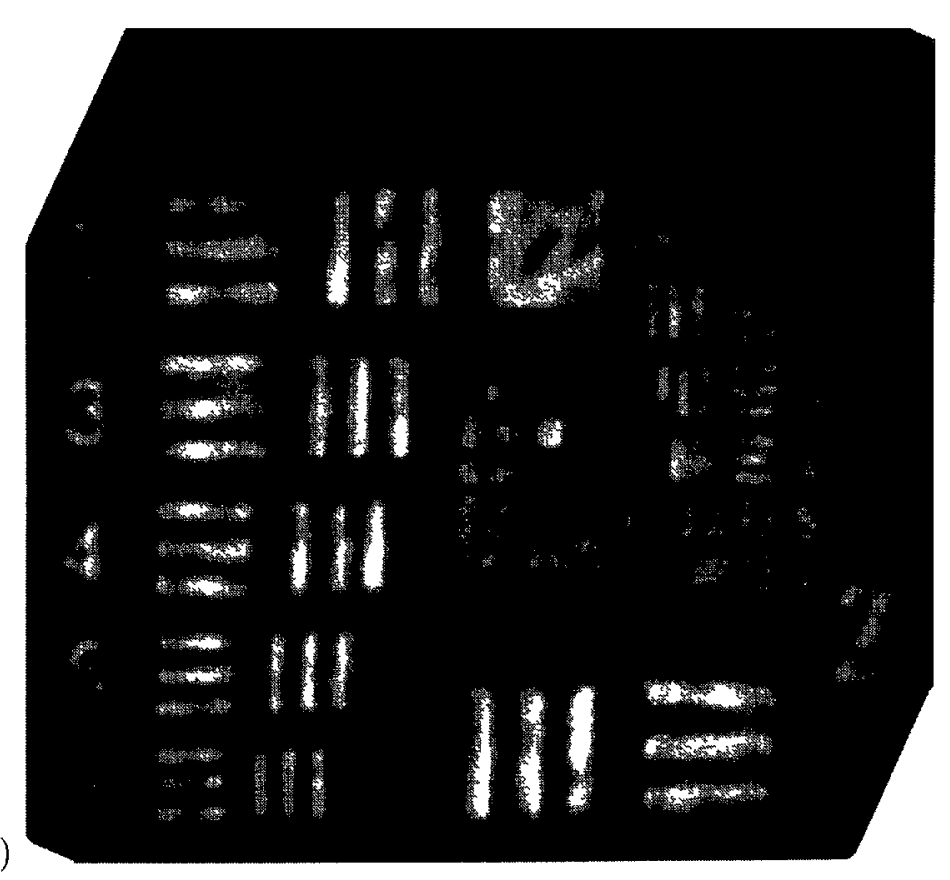

b)

Fig. 3 - The central part of the test chart seen through the camera (a), the best reconstructed image in Series IV (b) and in Series VI (c). 


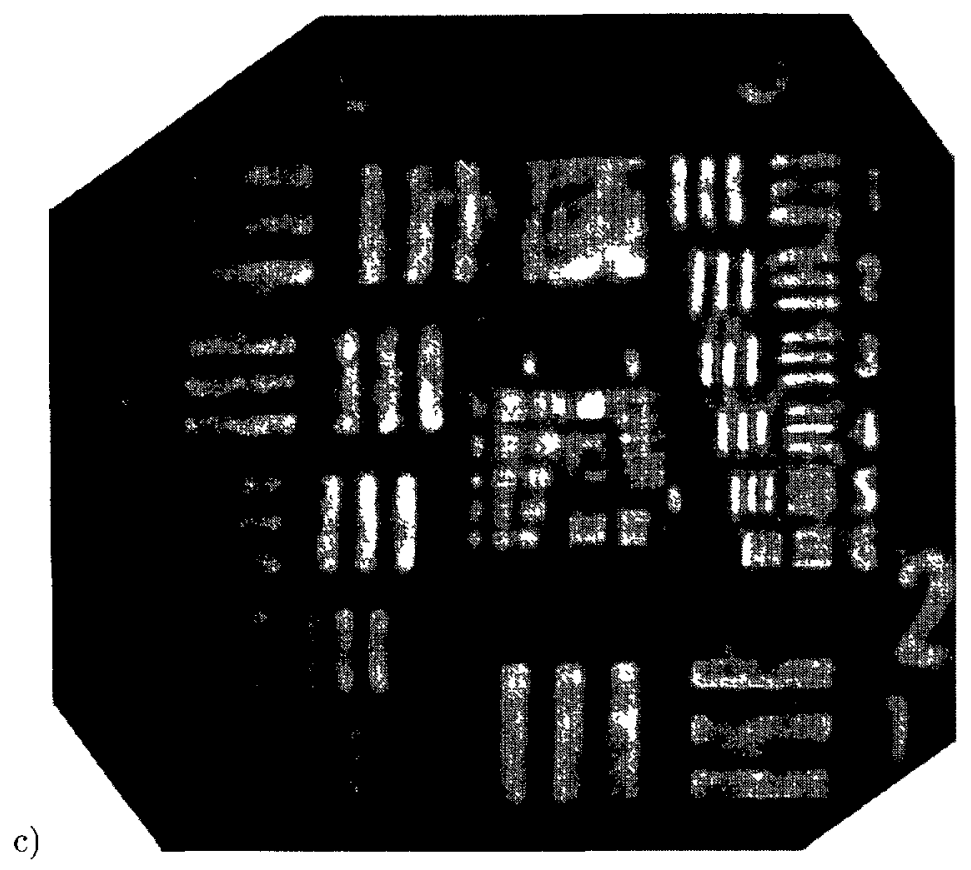

Fig. $3-$ (Contınued).

The image shown in Figure 3b, was reconstructed from a hologram recorded with a reduced driving current of $75 \mathrm{~mA}$ of the laser diode. The exposure time was $210 \mathrm{~s}$. A hologram recorded at almost full laser power $\left(I_{\mathrm{L}}=130 \mathrm{~mA}\right)$ produced the image is shown Figure 3c. The exposure time was reduced to $100 \mathrm{~s}$. The presence of noise is more pronounced in the latter figure, due to its higher brightness. Inspection of the original video images showed that, in the best reconstructed images, element $N^{\circ} 4$ of group $\mathrm{N}^{\circ} 4$ was the smallest resolved feature that corresponded to a resolution of 22.62 line pairs $\mathrm{mm}^{-1}$ (or a linewidth of $22.1 \mu \mathrm{m}$ ).

The ultımate resolution of these holograms can be determined by either a direct or a microscopic photoelectric scan [17] or an infrared-sensitive photographic emulsion and microdensitometer. Since such equipments were not available, the reconstructed real image was measured directly by the CCD array in the second part of the experiments. The polarization of the constructing beams was parallel to the plane of incidence in these experiments. At reconstruction, a high quality mirror (with a flatness better than $\lambda / 4$ ) was used to produce the conjugate of the reference beam. Several series of holographic images of the USAF 1951 resolution test chart were recorded. The recording conditions were as follows: object-to-hologram distance $R_{0}=60 \mathrm{~mm}$. The lengths of the horizontal and the vertical axes of the hologram were 10.0 and $150 \mathrm{~mm}$. The angle of incidence of the object beam was changed to $\alpha_{0}=10^{\circ}$, and that of the reference beam to $\alpha_{\mathrm{r}}=-30^{\circ}$ so as to reduce the effects of spurious reflections. The intensity of the reference beam was $29.5 \mathrm{~mW} \mathrm{~cm}^{-2}$, while the average intensity of the object beam in the hologram plane was $5.0 \mathrm{~mW} \mathrm{~cm}^{-2}$. Two reconstructed images of the test chart are shown in Figures $4 \mathrm{a}$ and $4 \mathrm{~b}$ The dye concentration in the sample was $1.13 \mathrm{mg} \mathrm{g} \mathrm{g}^{-1}$, the prepolymerization time and exposure time were $t_{\mathrm{pp}}=40 \mathrm{~s}$ and $t_{\exp }=240 \mathrm{~s}$ for Figure $4 \mathrm{a}$. The recording conditions of the hologram shown in Figure $4 \mathrm{~b}$, were: dye concentration: $1.33 \mathrm{mg} \mathrm{g}^{-1}, t_{\mathrm{pp}}=40 \mathrm{~s}$ and $t_{\mathrm{exp}}=360 \mathrm{~s}$. The noise in these images was much less than in those 
a)
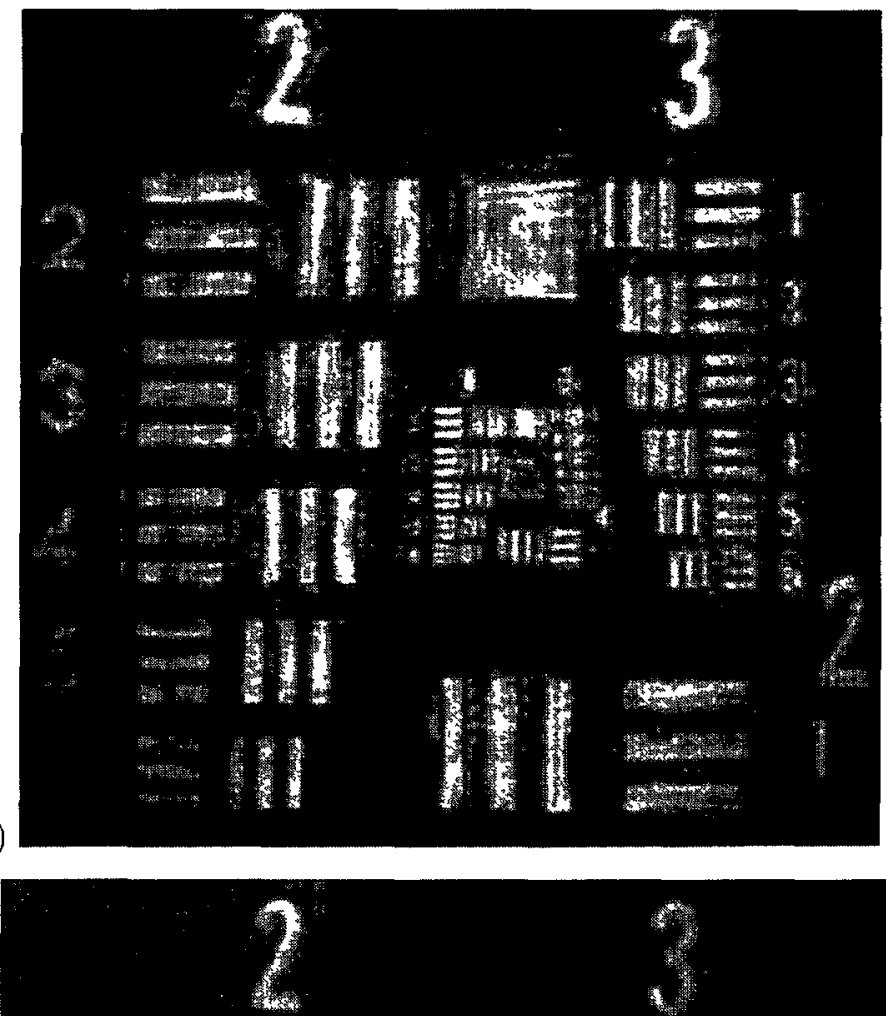

b)

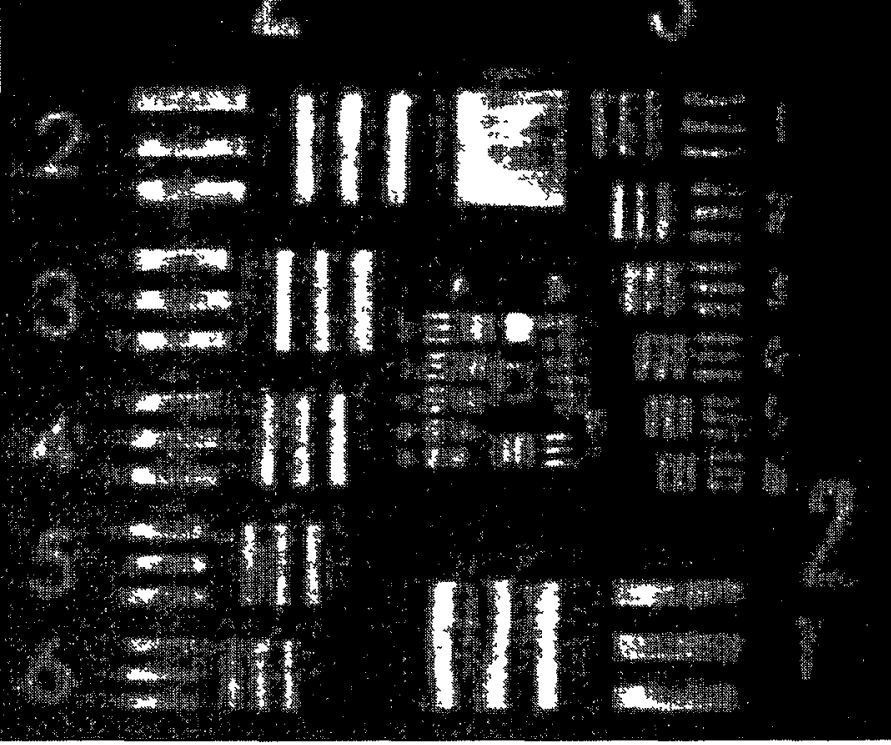

Fig. 4 - a), b) Reconstructed images of the test chart captured directly by the CCD array.

observed through the objective of the camera. Element $\mathrm{N}^{\circ} 6$ of group $\mathrm{N}^{\circ} 6$ that corresponds to 28.51 line pairs $\mathrm{mm}^{-1}$ (or a linewidth of $17.5 \mu \mathrm{m}$ ) was resolved in these images.

The USAF 1951 resolution test chart consists of a great number of periodic structures. It is very probable that intermodulation noise greatly reduces the resolution of the holographic 


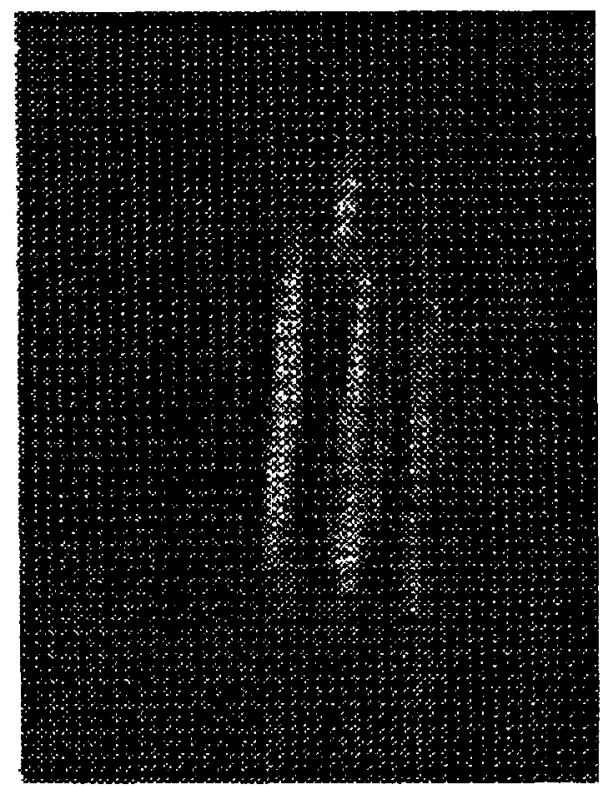

Fig. 5. - Reconstructed image of a three-element Ronchi grating. Linewidth $=8 \mu \mathrm{m}$

images of that object. To further improve resolution, we used an individual three-element Ronchi grating consisting of $8 \mu \mathrm{m}$ wide and $300 \mu \mathrm{m}$ long vertıcal lines. The recording conditions were the following: $R_{0}=48 \mathrm{~mm}$, hologram width $L_{x}=8 \mathrm{~mm}, \alpha_{0}=10^{\circ}, \alpha_{\mathrm{r}}=-30^{\circ}$, dye concentration $=0.93 \mathrm{mg} \mathrm{g}^{-1}, \bar{I}_{\mathrm{r}}=28 \mathrm{~mW} \mathrm{~cm}^{-2}$ and $I_{0}=3.15 \mathrm{~mW} \mathrm{~cm}^{-2}$. The best reconstructed real image is shown in Figure 5. It was recorded by taking $t_{\mathrm{pp}}=240 \mathrm{~s}$ and $t_{\exp }=600 \mathrm{~s}$. Since the pixel size of the CCD was comparable to the linewidth of the object, it was not easy to observe the reconstructed image, but as shown in Figure 5, the three lines were resolved.

2.3. Real-Time Holographic InTerferometry. -- Since this IR sensitive photopolymer material does not require any processing, it can be used for real-time holographic interferometry with a laser diode. The first successful experiments were carried out by using the same set-up as for the assessment of the holographic characteristics and imaging capabilities of this material.

The gradient of refractive index resulting from the dissolution of $\mathrm{NaCl}$ in water was used to exemplify these capabilities. A cuvette was filled with distilled water and placed in the object beam in such a way that the region just above the bottom was transilluminated. To start with, a hologram of this phase object was recorded. The object and the hologram being both kept in their original positions, the interference between the wavefronts coming from the object and its virtual holographic image was filmed with the CCD camera. A frame of a quasi fringe-free interferogram is shown in Figure 6a. The curved spurious fringes are due both to the reflections at the different lens surfaces in the objective and the volume shrinkage of the polymer. A small amount of $\mathrm{NaCl}$ was, then, introduced into the cuvette. The position of the real-time interference fringes one minute later is displayed in Figure $6 \mathrm{~b}$. The solution was still far from equilibrium, the meandering of the fringes is due to the uneven distribution of the salt on the bottom of the cuvette. Traces of emerging gas bubbles can also be seen. Another amount of salt was, then, added to the solution. Figure 6c, was recorded a few seconds later. 


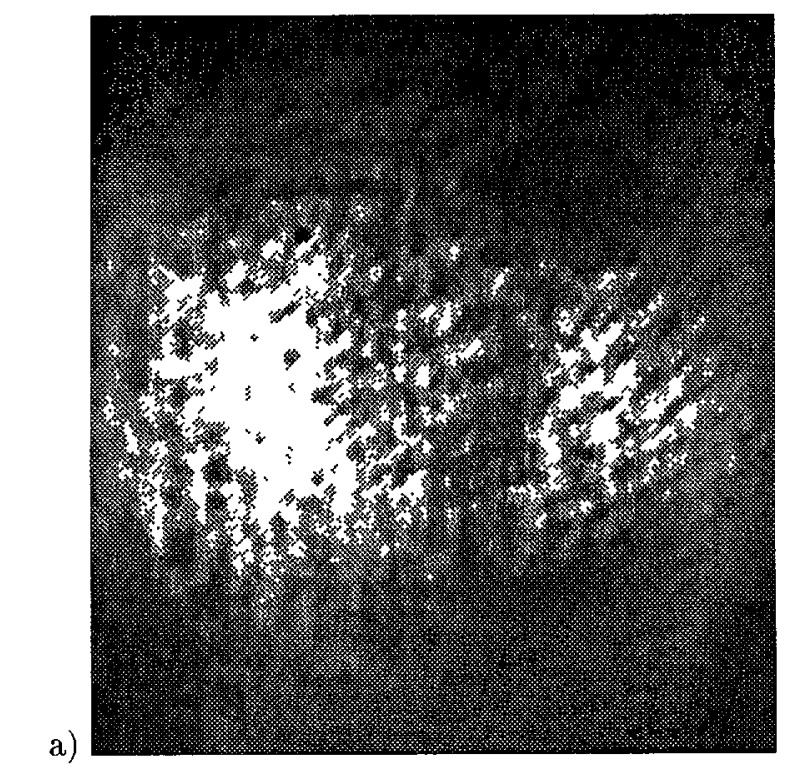

b)

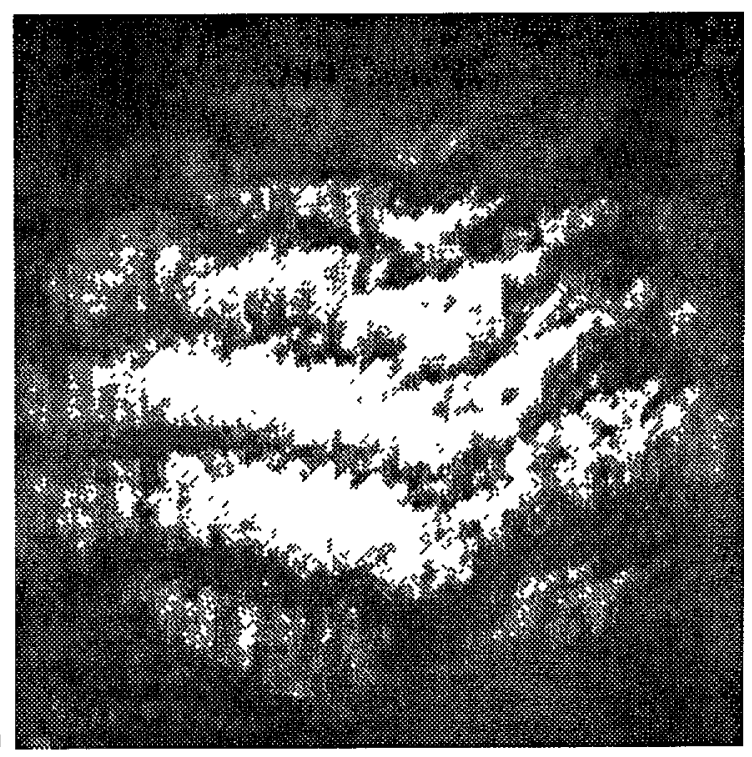

Fig. 6. - a) Interferogram recorded before introducing $\mathrm{NaCl}$ into the water, b) interferogram recorded one minute after adding $\mathrm{NaCl}$ to the water, c) interferogram recorded 4 seconds after adding a new dose of $\mathrm{NaCl}$ to the solution, d) interferogram recorded 25 minutes after adding the second dose of $\mathrm{NaCl}$ to the water.

An intricate system of fringes (partially obscured by bubble traces) is apparent in this picture. Figure 6d, was taken 2.5 minutes after the second introduction. The reduced fringe spacing results from the considerable increase in refractive index gradient when salt was added to the solution. 
c)

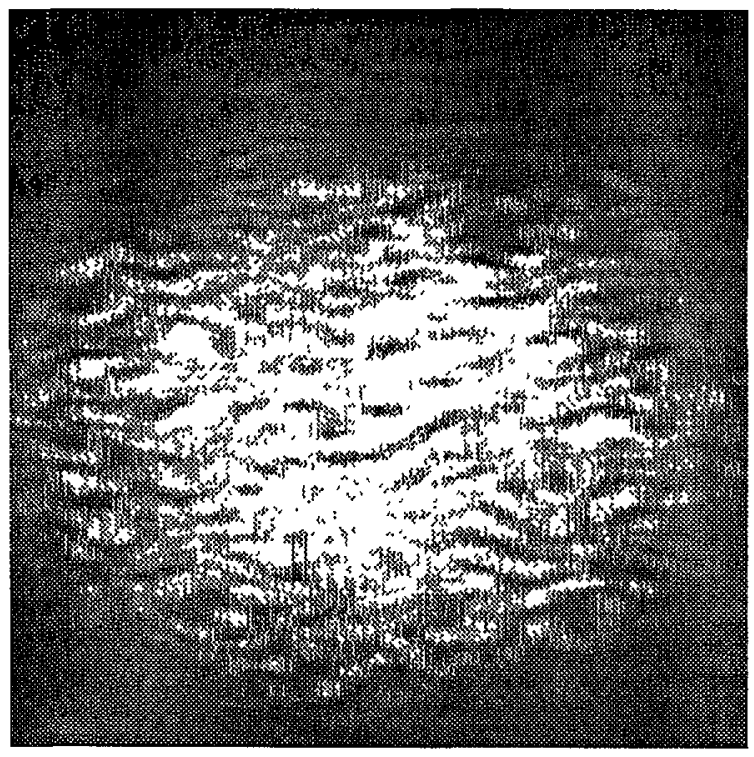

d)

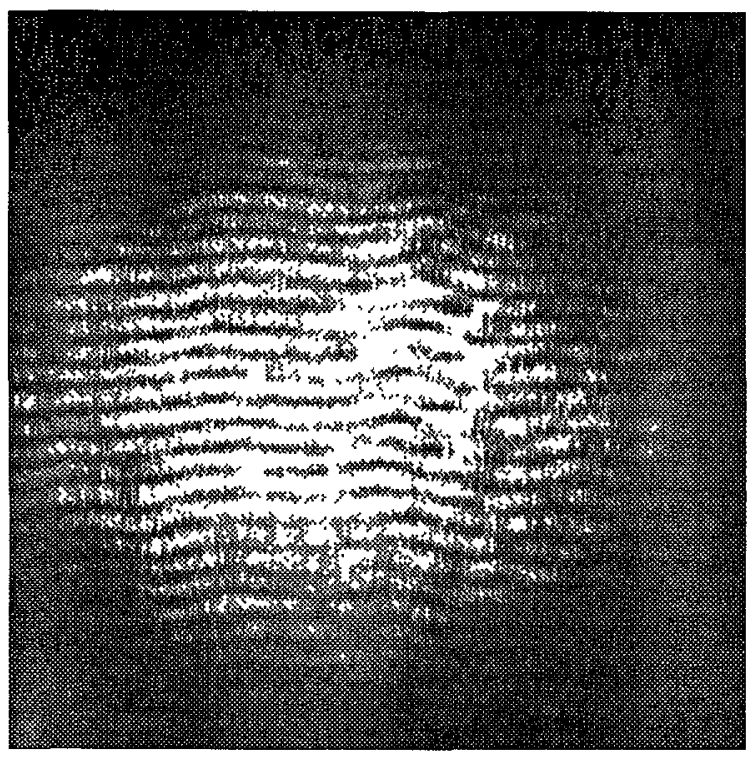

Fig. 6. - (Contınued).

The vertical distribution of the refractive index resulting from the dissolved sodium chloride can easily be derived from the interferograms by using the following general equation.

$$
\Delta \Phi(x, y)=k_{0} \int\left[n(x, y, z)-n_{0}\right] \mathrm{d} z
$$

where $\Delta \Phi(x, y)$ is the phase difference at any point of the test section, $k_{0}=2 \pi / \lambda, n_{0}$ the refractive index of the medium in its initial, unperturbed state and $n(x, y, z)$ the final refractive index distribution, on the assumption that the llumination is parallel to the $z$-axis. 
Although the unprocessed interferograms shown in Figure 6 do not have a good visibility, it is hoped that high contrast fringes could be obtained by appropriate modification of the recording conditions and postprocessing of the images.

As for other potential applications of this material in holographic interferometry, good results can also be expected in time-averaged holographic interferometry, too. However, it is not suited for double exposure holography of rapidly changing scenes due to the relatively long exposure times. Since photopolymer recording materials were successfully applied in polarization holography [13], applications for the interferometric study of stress induced birefringence may also be anticipated.

\section{Conclusion}

A new formulation, suitable for holographic recording at $780 \mathrm{~nm}$ was developed and tested. It was found that bright holographic images of good spatial resolution could be recorded in this material. The measured highest diffraction efficiencies were between $60-70 \%$ at $543 \mathrm{~nm}$ and around $25 \%$ at $780 \mathrm{~nm}$. The extent of the prepolymerization exposure is a crucial factor in hologram recording. The highest resolution achieved in our experiments was 62.5 line pairs $\mathrm{mm}^{-1}$. The holographic sensitivity of this material is approximately $0.11 \mathrm{~cm}^{2} \mathrm{~J}^{-1}$, depending on the concentration of the sensitizer. Real-time holographic interferometry with this new material has also been carried out. Construction of compact portable holographic interferometers based on the use of a laser diode and this material can be envisaged. Measurement of the MTF and the nonlinear exposure characteristics of the material could make it possible to predict and optimize the quality of the holographic image [18-21]. Implementation of these characteristics could lead to significantly improved diffraction efficiency and resolution of near-infrared holograms.

\section{Acknowledgments}

I. Bányász expresses his appreciation to the University of Haute-Alsace, France, for granting him a visiting professorship. Financial support from the Centre National d'Études Spatiales is gratefully acknowledged.

\section{References}

[1] Biedermann K., Silver Halide Photographıc Materıals, In "Holographic Recording Materials", H.M. Smith, Ed. (Springer, Berlin, 1977) pp. 49-50

[2] Close D.H. et al., Hologram recording on photopolymer materials, Appl. Phys. Lett. 14 (1969) 159.

[3] Jenney J.A., Hologram recording with photopolymers, J. Opt. Soc. Am. 61 (1970) 1116.

[4] Hariharan P., Hologram recording materials: recent development, Opt. Eng. 19 (1980) 636.

[5] Sugawara S., Dye-Sensitized Photopolymerizable Materials for Hologram Recording, Rev. Electrucal Commun. Lab. 24 (1976) 301.

[6] Oliva J., Mateos F. and Pastor C., Dye-Sensitized Photopolymers in making real-time holographic interferagrams, Opt. Pura y Apl. 18 (1985) 193. 
[7] Ingwall R.T. and Troll M., The mecanism of hologram formation in DMP-128 photopolymer, Opt. Eng. 28 (1989) 586.

[8] Smothers W.K., Monroe B.M., Weber A.M. and Keys D.E, Photopolymer for holography, Proc. SPIE 1212 (1991) 20.

[9] Carré C., Ritzenthaler D., Lougnot D.J. and Fouassier J.P., Biphonic process for recording holograms with continuous-wave lasers in the near infrared, Opt. Lett. 12 (1987) 646.

[10] Lougnot D.J., Ritzenthaler D., Carré C. and Fouassier J P., A new gated system for two-photon holographic recording in the near infrared, J. Appl. Phys. 63 (1988) 4841.

[11] Carré C. and Lougnot D.J., Photopolymerizable material for holographic recording in the 450-550 nm domain, J. Optics 21 (1990) 147.

[12] Lougnot D.J., Noiret N. and Turck C.N., Photopolymers for holographic recording: IV. New self-processing formulations based on $\beta$-hydroxy ethyloxazolidone acrylate, Pure Appl. Opt. 2 (1993) 383.

[13] Carré C., Defosse Y. and Lougnot D.J., Use of a self-developing polymer material for volume reflection hologram recording, Pure Appl. Opt. 2 (1993) 437.

[14] Carré C., Habraken S. and Roose S., Computer-originated polarizing holographic optical element recorded in photopolymarizable layers, Opt. Lett. 18 (1993) 738.

[15] Carré C. and Lougnot D.J , Photopolymers for holographic recording: from standard to self-processing materials, J. Phys. III France 3 (1993) 1445.

[16] French Patent No. 910846 of $05 / 07 / 91$, assigned to CNET of France.

[17] Bányász I., Kiss G. and Varga P., Holographic image of a point source in the presence of misalignment, Appl. Opt. 27 (1988) 1293.

[18] Bányász I., The effects of the finite spatial resolution of thermoplastic recording materials in the holographic image, J. Phys. III France 3 (1993) 1435.

[19] Bányász I., Evaluation of the imaging properties of holograms recorded in materials of limited spatial resolution, Opt. Eng 32 (1993) 2539.

[20] Bányász I., Method for the evaluation of the effects of film nonlinearities on the holographic image, Opt. Lett. 18 (1993) 658.

[21] Bányász I., Fimia A., Beléndez A. and Carretero L., Nonlinear recording of amplitude holograms in agfa 8E75HD: comparison of two developers, Opt. Communications 111 (1994) 225. 